\title{
Agnes Franzen, Fred Hobma, Hans de Jonge and Gerard Wigmans (eds): Management of urban development processes in The Netherlands: governance, design \& feasibility
}

Techne Press, Amsterdam, 2011, 247 pp, ISBN 978-90-8594-029-6

\author{
Anita Kokx \\ Published online: 6 June 2012 \\ (C) The Author(s) 2012
}

Urban area development, as seen for instance in the renewal of inner-city areas and the transformation of port, rail and industrial areas, has become prominent in Dutch urban planning practice over the past 30 years. It involves not only various types of government intervention, such as formulating a vision, plans and regulations, but also co-operation with private parties and citizens-in other words, urban governance. To be successful, these processes need to be adequately managed. The aim of "Management of Urban Development Processes in the Netherlands" is primarily to provide Dutch students and practitioners in the field with an understanding of current practice and give an overview of the expertise acquired so far and of the instruments developed in the Netherlands. The editors have explicitly chosen the governance perspective (planning, management, co-ordination and organisation) as a framework for managing networks in urban area development.

The starting point of the book (Chapter 1) is that urban area development is complex due to the multi-actor setting and the changing social and policy contexts. These conditions have made the management of these processes increasingly complex. Chapter 2 sets out the theoretical framework in more detail, referring to such issues as the new network society (Manuel Castells) and global economic restructuring (Saskia Sassen) and their implications for cities. More specifically, the chapter cites David Harvey's concept of the entrepreneurial city with its characteristic fragmentation due to market-led, project-oriented urban development. Within this context, the editors elaborate on the governance concept, which entails public-private partnerships and process management to achieve "integrated area development". In other words, its goal is to achieve coherence between physical-spatial, economic and socio-cultural aspects of urban development.

Chapter 3 focuses on the management of urban development and the concept of organising capacity as a development strategy. The Dutch authors critically examine the limitations of this consensual approach, noting the problems of conflicting interests and diverging frames of reference among the different actors involved. They offer another theoretical perspective, one stressing the diverging objectives, diverging contexts and the importance of urban conflict management as integral features of these governance processes.

\footnotetext{
A. Kokx $(\bowtie)$

Department of Human Geography and Planning, Utrecht University, Utrecht, Netherlands e-mail: J.M.C.Kokx@uu.nl
} 
Moving beyond this rather theoretical section, the following chapters focus on several aspects of Dutch urban area development, including process architecture, financial engineering, market influences and spatial quality. Most of these topics are illustrated with interesting examples of interventions in different contexts. These case studies provide the reader with an understanding of the complex background of urban area development in the Netherlands and the challenges it poses to urban management. In each chapter, the authors draw conclusions with respect to the subject under review.

The final chapter presents the book's conclusion on the success factors in urban area development from a governance point of view. It distinguishes context variables (economic, political, socio-cultural and institutional), veto criteria (e.g., land ownership, project scope, market demand and finance) and critical success factors (e.g., trust, leadership, proactiveness and policy makers).

The book would certainly make stimulating reading for students and interested practitioners. It offers them an introduction to the complexity of urban area development in the form of richly described case studies and different scientific points of view. Whereas an attempt has been made to integrate various chapters, the reader may find the structure rather fragmented and sometimes lacking in coherence. For example, some authors (van Hoek and Wigmans) start with a straightforward theoretical introduction to the subject, illustrate it with case studies, draw conclusions and critically reflect on the theoretical framework they have used. Others, however, are much less concerned with the theoretical implications. Not surprisingly, the contributions of the latter are rather descriptive and lack the analytical depth and explanatory strength one might expect. The book's lack of theoretical ambition is revealed in the first two chapters. There, the focus is on the more general (and well-known) concepts of the network society and networks rather than on the various theoretical dimensions of urban governance, such as multi-level governance, ambiguity in perceptions and power dimensions. In that regard, the book falls short: it does not offer a critical scientific reflection on the normative governance literature, notably on such issues as the reality of neo-liberalism, dominance and distrust, and the exclusion of citizens as stressed by authors such as Neil Brenner, Bob Jessop, Jonathan Davies, Janet Newman, Erik Swyngedouw, and Marilyn Taylor. Furthermore, the book fails to make the link to the critical scientific international governance debate: it is a handbook for students on the complexity of Dutch urban area development, rather than an academic textbook-it could have given much more attention to the current (and extensive) body of international scientific literature on urban governance and to the inherent power-struggles of urban governance practice.

Finally, the editors could have devoted more attention to the changing context of urban area development as a result of the economic crisis in the Netherlands, to the subsequent crisis in the country's real estate market and its decreasing government budgets. Several chapters offer some general recommendations for a more tailor-made approach. However, the question is whether this changed context would actually require a fundamentally different perspective on urban area development and urban governance in the future. Would the more bottom-up approach of self-organisation be more appropriate? If so, what role would urban management play? Whilst the book provides a sound basis for research on this topic, from a scientific and practical point of view, a great deal of work still has to be done to bring urban area development and urban governance a step further in an ever-changing context.

Open Access This article is distributed under the terms of the Creative Commons Attribution License which permits any use, distribution, and reproduction in any medium, provided the original author(s) and the source are credited. 